\title{
How and When Advertising Can Influence Memory for Consumer Experience
}

\author{
Kathryn A. Braun-LaTour, University of Nevada Las Vegas \\ Michael S. LaTour, University of Nevada Las Vegas \\ Jacqueline E. Pickrell, University of Washington \\ Elizabeth F. Loftus, University of California-Irvine
}

Recent "paradigm shifting" research in consumer behavior dealing with reconstructive memory processes suggests that advertising can exert a powerful retroactive effect on how consumers remember their past experiences with a product. Building on this stream of research, we have executed three studies that incorporate the use of false cues with the aim of shedding new light on how post-experience advertising exerts influence on recollection. Our first experiment investigates an important but yet unexplored issue to advertisers who are perhaps reticent about embracing this paradigm: Does the false cue fundamentally change how consumers process information? After finding that when the false information goes undetected it is processed in a similar manner as more "truthful" cues, we use this paradigm to shed light on the pictorial versus verbal information debate in advertising. We discuss the implications of our findings for those interested in managing consumer experience and for advertising researchers seeking indirect measures of the influence of advertising.

Remember your childhood visit to Disneyland? - Cinderella's castle glistening, the cartoon characters laughing, grouping for photos, the many rides with their height requirements, the smells of freshly cooked food, and Bugs Bunny shaking your hand? As you bring that experience to mind, you may have the feeling you are reliving it, seeing your childhood pass through your mind's eye, much like reviewing a video-tape. But the way human memory works is very different from that of a video tape recorder-our memories are actually re-constructions of bits and pieces of information we have obtained over time. Sometimes those reconstructions are very similar to what we experienced; other times we are "tricked" and remember things differently than how they actually happened. Bugs Bunny is not a Disney character, yet some people "remember" him as being part of their childhood experience 
after hearing that suggestion. What leads to such memory alterations, and what if they could be directed by advertisers?

The nature of consumer experience has been an area of interest to advertising researchers because of the interesting paradox it presents: Experiences have the potential for malleability and manipulation, yet consumers trust their experiences most within their decision making (Hoch 2002). Advertisers have been interested in ways in which they can "transform" the nature of the consumer experience by setting expectations that influence the way consumers attend to in-formation (Hoch and Deighton 1989). As Wells puts it: "Advertising helps consumers interpret these experiences. It suggests what should be noticed. It provides cues and clues to help consumers understand and appreciate their feelings. And in this way it can change the nature of the response" (1986, p. 9). When advertising works in this manner, it can exert an insidious effect on consumer behavior. For instance, a classic experiment done by Olson and Dover (1979) found that advertising received prior to a bitter coffee experience made consumers tolerate and appreciate the taste more than those who did not receive the advertising.

Most of the research that has investigated how advertising can influence experience has assessed "forward framing," where the advertising is presented before the experience (e.g., Boulding et al. 1993; Deighton 1984; Deighton and Schindler 1988; Olson and Dover 1979). More recent research, how-ever, suggests that advertising received after an experience can exert an impact by influencing how that experience is remembered (Braun 1999).

Although the effect of post-experience advertising on consumer memory has been demonstrated (Braun 1999), we still know very little about what is leading to those effects, such as what type of advertising will have the most influence on consumer memory. Nor do we know the boundary conditions of this effect: Might there be a point where advertising can go too far in its attempt to reframe the past? These questions are important to advertising researchers, because the opportunities for advertisers to shape experiences after they have transpired are quite common, as most advertising is for mature products - those for which consumers have already had an experience.

Market-level data finds that advertising is noticed more after a consumer has used a product (Lodish et al. 1995), per-haps due to dissonance reduction. In fact, there is a whole type of advertisingnostalgia-that works by referencing aspects of consumers' past experiences (e.g., Baumgartner, Sujan, and Bettman 1992). Furthermore, due to reconstructive processes in memory, the influence of advertising on consumers' recollections of the past is likely to be greater than their ability to transform the future (Schacter 1996). 
The reconstructive view of memory has been well established within psychology, neuroscience, biology, and now marketing research, but there is an implicit belief in the advertising literature that consumer memory is based on a re-productive store (e.g., Ehrenberg et al. 2002). We therefore begin the present study by distinguishing between reproductive and reconstructive views of memory, and review moderators from the cognitive psychology literature that appear to influence the way postexperience can be used to modify an existing memory. We incorporate these factors into our discussion of post-experience advertising design, specifically regarding pictorial versus verbal information presentation. Because measurement of advertising's influence on memory is critical, we present several different methods for elucidating the effects that advertising has on memory for past experiences. We then present three studies that investigate advertising's retroactive influence on consumer memory, and discuss their significance for advertising researchers.

\section{Background}

\section{Reproductive versus Reconstructive Memory}

Sir Frederic Bartlett (1932) early on suggested that memory was not merely a reproduction of past experience, but rather a complex reconstruction by which we give meaning to our experiences, influenced both by what we knew before the experience transpired and what we learned afterward. He believed that in order for us to make a sensible picture of our world, it might only be natural that the memory system mix fact with interpretation in such a way that they become indistinguishable.

In contrast, the traditional reproductive theories of memory imply that stored mental representations of past experiences are elicited intact during recall (Reber 1985). This viewpoint is implicit in how advertisers model the effects of advertising, believing that a one-to-one correspondence exists between what was seen and what can be later retrieved, and that once memory reaches longterm storage, it is always accessible.

Ehrenberg and colleagues state:

Once a message or image is placed in our long-term memory, it seems virtually never to be forgotten (e.g., Hunter 1964; Franzen and Bouwman 2001). Formal recognition tests and general experience have long confirmed this (e.g., recognizing the picture seen once 20 years ago, or the first chord of Beethoven's Seventh, for those who know the Seventh). The capacity of our memory is without question vast-each of us routinely remembers so much. (Ehrenberg et al. 2002, p. 10) 
Advertisers have been urged to find the appropriate "cue" so that consumer memory can be unlocked and used in decision making (Keller 1987, 1991). This traditional view assumes that a retrieval cue merely arouses or activates a memory that is slumbering in the brain. Within the advertising domain, consumers are thought to have a memory trace for the ad and a memory trace for their experience, which are separate and in-dependent entities; any failure to remember either type of information is due to faulty retrieval cues (Ehrenberg et al. 2002).

The reconstructionist view, meanwhile, finds that such related information may combine together so that when a past experience is recalled, the advertising information may infiltrate that memory. We believe that when the advertising has become internalized in this manner and becomes part of the consumer's own memory, this represents the ultimate in advertising persuasion-the consumer now owns the advertising material.

The reproductive view is intuitively appealing, and the emotion or vividness associated with bringing a past memory to mind may provide us an illusion of its veracity; however, failure to recognize memory's reconstructive nature can lead advertisers in wrong directions. For example, assuming past experience is veridical, an advertiser may not target consumers who had a past bad experience with their product and could therefore miss out on an opportunity to win them back. Or believing that a positive memory will always be so, an advertiser may leave the unassuming category leader open to competitors who try to engineer their own relationships/histories with customers.

To differentiate the traditional reproductive view of memory from the reconstructionist view, one has to show that post-experience information can alter how the consumers remember the experience. Within cognitive psychology, there has been a large stream of research dedicated to doing just that; these researchers find that post-experience information can influence memories for prior experiences, ranging from the alteration of details to the creation of entirely false experiences (Loftus 1982).

To apply the false memory research from psychology to the typical advertising situation, we assert that the processes consumers use as they retrieve memories do not differ de-pending on the veracity of the information. Research finds that when people retrieve both true and false memories, similar brain regions are activated, so that those recalling a false memory have the same sense of confidence and belief in their recollection as those who were recalling an accurate memory (Schacter 1996). We suggest that where the processes differ is during encoding. Research finds that when people notice the falsity of the claim at encoding, they are much less likely to be influenced at retrieval (Dodson and Schacter 2001; Loftus 1979). Therefore, one way to assess the influence of advertising acceptance is 
to ascertain at the ad presentation precisely who notices the falseness of the advertising and who does not.

\section{Types of Information}

Not all post-experience cues are equivalent in their ability to conjure up the past. From the welldocumented research in cognitive psychology, we can extract some guidelines for the type of information that works best in influencing memories. For instance, the more similar the suggested postexperience activity is to what people actually experienced, the more likely source confusion may occur and result in memory distortion (Johnson et al. 1988). In addition, the more credible the source-for example, a police officer versus a "goofy man" providing the details-the more likely the postexperience information will be accepted and integrated into one's original memory (Lampinen and Smith 1995).

More plausible post-experience information (for example, suggesting something that potentially may have happened, such as meeting Mickey Mouse at Disney World) is much more likely to influence one's memory than if the claim seems implausible (such as encountering aliens at the park) (Pezdek, Finger, and Hodge 1997). The more times one receives the post-experience information, the more familiar it becomes, and the more likely it will be taken as fact and integrated into memory (Zaragoza and Mitchell 1996). Within the experimental setting, it has been found that false post-experience information will more likely be accepted if it is subtle and the participants do not notice the discrepancy (Tousignant, Hall, and Loftus 1986).

\section{Advertising Issues}

The research on reconstructive memories within a marketing context is much newer than that in psychology, with much of the emphasis being on whether or not advertising can, in fact, influence a consumers past experience because of its low credibility. Once advertising was found to influence the past (e.g., Braun and Loftus 1998), the interest was in what type of experience could be altered through post-experience information, as in whether a really negative experience could be made to seem better in retrospect (Braun 1999).

Only recently has there has been an interest in what types of advertising execution-such as autobiographical referencing-might influence the past (Braun, Ellis, and Loftus 2002). There has been

little research on determining the "boundary effect" of misinformation, that is, the point at which it will be detected and not influence the original memory. 
The choice of executional style utilized in the present re-search began with where that prior research on autobiographical advertising left off. Researchers have found that consumers need a motivating cue to recollect their past experience (Baumgartner, Sujan, and Bettman 1992), and that this can best be done through an autobiographical advertisement. Autobiographical ads that are emotionally arousing and en-gaging have been found to be effective for memory reconstruction to occur (Braun, Ellis, and Loftus 2002). In fact, this is consistent with research in forward-framing literature, where drama ads that show the product in use have been linked to transformational effects (Boiler 1990; Wells 1986), and ads with high affective content have been linked to this process as well (Aaker and Stayman 1992).

The issue we chose to specifically concentrate on for the present research was how to represent the target information within the ad itself. For a print ad, there are two ways this can be done: verbally or pictorially. Traditionally, the false memory research has used verbal cues, touting a modality-free view of semantic memory (Pezdek 1977).

Within advertising, there has been a long-standing debate about whether information is conveyed better through pictorial or verbal means. There had been a bias to convey important information in explicit verbal form (Rossiter and Percy 1980). Stafford (1996) found that verbal cues outweighed pictorial ones for conveying information about a service experience. Smith (1991) found that inferences derived from advertising copy were stronger than those derived from pictures. Edell and Staelin (1983) found that verbal cues were necessary for pictures to be processed and later remembered, and in a similar vein, Phillips (2000) found that headlines helped people interpret complex pictures and enhanced the ad's likeability.

However, other researchers support the well-known picture superiority effect on memory (e.g., Childers and Houston 1984; Gardner and Houston 1986) where there is an advantage for information presented as a picture over words. For example, while generally supporting the importance of inferences made from ad copy, Smith (1991) found that when verbal and pictorial information were at a mismatch, people tended to rely on the pictorial information.

Hirschman (1986) found that pictures in ads made people feel more familiar with products than did verbal information. Yi (1990) found that pictorial cues helped enhance product beliefs, and when they were absent, persuasion was more effective through indirect verbal means.

Thus far, the false memory research does not provide much insight into how the modality will influence how the advertising information will be embraced and internalized as one's own memory. For instance, in support of the modality-free view of semantic memory, Braun and Loftus (1998) presented 
misinformation in an advertisement either as a picture or words, and found about equal levels of false memories across conditions.

In addition, when dealing with a piece of information that is quite blatantly false to some consumers, one might argue that misinformation that is less detectable may float under the consumers' conscious radar screen and be adapted. As Loftus and Pickrell state: "New information invades us like a Trojan horse, precisely because we do not detect its influence" (1995, p. 720).

On the other hand, when dealing with a memory of an experience that has transpired many years ago (as opposed to Braun and Loftus [1998], whose experience occurred fifteen minutes earlier), pictures or images can trigger stronger "remembering" (Schacter et al. 1996). Rossiter and Percy (1980) found that pictorial content in advertising is especially capable of stimulating pictorial imagery. According to Bartlett (1932), an image is a device for picking out bits of schemes from memory, and increases the chances of variability in the reconstruction of a past event. When people recount past experiences, they often begin by pictorializing perceptual de-tails and embellishing based on those details (Belli and Loftus 1996).

While Braun and Loftus (1998) found no difference be-tween modalities in the total number of false memories created, the pictorial information led to stronger "remembering" judgments (where participants stated they could see the candy bar in their mind's eye). Recently, Wade and colleagues (2002) found that doctored photographs led to an exceptionally high rate of creating false autobiographical memories. Clearly, the issue of information modality is an important one to advertising researchers interested in evoking and directing aspects of consumers' past, but it is in need of additional study.

\section{Assessing Influence}

According to Clark, "Asked about the power of advertising in research surveys, most agree it works, but not on them" (1985, p. 13). This statement represents one of the problems with research on advertising effects: People do not want to admit they have been influenced. In other cases, they may not realize they have been influenced, because that influence operated below their conscious awareness (Zaltman 1997). To get a better understanding of how advertising works, there is a need to find indirect measures that take into account the complexity of human memory (Hall 2002).

This research proposes looking at the transformation of consumer experience indirectly through the memories influenced by the ad s exposure. Cognitive psychologists have developed the "misinformation paradigm," where participants experience an event, such as seeing an accident. Next, 
some participants are given misinformation, such as pro-viding false information about the accident, while others are given no such information. Last, participants are tested for their memory of the original experience. Those who have incorporated the false information into their memory are said to have a "misinformation effect" or "false memory" (Loftus 1977).

This same misinformation paradigm has been applied to advertising situations, both with a very strict replication (Braun and Loftus 1998) and with more leniency (Braun 1999). As found in the psychological arena, those who incorporate information from advertising received after an experience have created a "false memory." While we are certainly not suggesting that advertisers ought to consciously seek to alter consumers' memories (this may be happening nevertheless, due to the reconstructive nature of recall), we propose that this paradigm allows us to determine when advertising will have an effect on how consumers remember their past experiences. It is important theoretically to include false information in the post-experience advertisement to determine whether the ad is merely awakening an existing memory (as the current implicit view of reproductive memory might state) or having an influence on the reconstruction process. For instance, the incidence of distorted or false memories across advertising conditions serves as a measure of advertising's influence on consumers' pasts.

Because of the need for ecological validity in their results, cognitive psychologists have moved from strictly controlled settings where both the experience and misinformation are manufactured, to more natural environments where the post-experience information seeks to influence participants' actual pasts (e.g., Garry et al. 1996). Following the strictly con-trolled experiments of Braun (1999), Braun and her colleagues have also moved in this direction. For instance, Braun, Ellis, and Loftus (2002) looked at how an autobiographical ad for Disney might alter how consumers remember their own childhood experiences there. This move represents a greater connection between the experimental testing of advertising's influence on reconstruction and how advertisers ultimately might incorporate these findings, but it does sacrifice some experimental control.

However, there is an important difference between the single-exposure controlled taste experience (Braun 1999) and the important autobiographical memories that are most of-ten referenced in advertising. Information about the self, such as important rituals (birthdays) or first experiences (visiting Disney as a child), tend to be remembered better than other information (Neisser 1982). In addition, there is also evidence that autobiographical memories may rely on different brain mechanisms than purely episodic memories (Schacter 1996), which means there is a possibility that what appears to influence a one-time episodic memory in a lab situation may be different than what influences 
autobiographical recall out-side the lab. Therefore, the current study continues down the realism path, investigating how advertising might influence one's memory of an important autobiographical eventvisiting Disney World.

The measurement of misinformation effects has become more sophisticated, allowing researchers to better differentiate processes involved in retrieval. Newer measurement devices based on implicit processes are used in the present studies, which could be used more generally for studying advertising effectiveness. For instance, response latencies pro-vide information about the accessibility of the memory data, with faster identifications generally indicating that material was more "top of mind" (Greenwald, McGhee, and Schwartz 1998). In addition, programs such as the Implicit Association Test (IAT) allow researchers to determine how well the advertising information has been incorporated into consumers' general knowledge (ibid.). In this test, participants categorize information. If the advertising changes how key items featured in the ad are later categorized, then one can determine whether the advertising is having an influence on semantic memory.

We posit that one of the problems with the discrepancies found in the aforementioned verbal versus pictorial debate in advertising may be due to measurement differences in the studies. Others have suggested that verbal processing requires more conscious thinking (Rossiter and Percy 1980), which may be better picked up on explicit tests of memory. For ex-ample, the research touting verbal superiority relies on inference processes, and is generally tested with verbal measures. In contrast, the research finding support for the importance of pictures suggests that the picture creates a sense of familiarity or positive affect toward the product.

In fact, more recent research suggests pictorial advertising information may "prime" consumers unconsciously, and could thus be measured more effectively with indirect or implicit tests (Schmitt 1994). Although we don't expect to offer a definitive answer on the modality debate, we do hope that some of the tools used in our experiments will shed light on this very complex issue.

\section{Research Questions and Study Overview}

To apply the false memory paradigm to advertising research, our first research question was whether advertising that contains false information would be processed in a similar way as "true" advertising. In Experiment 1, we use the same basic design that was used in Braun, Ellis, and Loftus (2002) to investigate this issue. Participants saw a Disney ad that either mentions Bugs Bunny (false information) or Mickey Mouse (true information), and then filled out some rating scales. Later they were asked about their own childhood visit to the park. 
We expected that those who received the "true" and "false" ads would rate the ads in a similar fashion, have similar attitudes toward Disney, and have relatively positive memories of their past experience at the park. The only aspect in which we expected a differentiation was in the degree to which participants would identify Bugs Bunny, the false cue, as having been part of their original experience. Because the Bugs Bunny reference may have been highly discrepant to some participants, we expected those who noticed the discrepancy (our "Bugs detectors") at advertising encoding to not be influenced by the advertising, and to provide us with a measure in which we could observe the boundary effects for advertising misinformation.

After demonstrating that this false memory paradigm is appropriate for studying how advertising information can transform consumer memories, our next research question was what type of information-pictorial or verbal, or a combination of both modalities-was leading to the memory changes. If consumers consciously need to attend to and use the false information as part of their retrieval process to be accepted, we would expect that more information would be better, where those participants who had received the false information in both pictorial and verbal form would have more created memories (Paivio 1971).

If it is better not to draw attention to the false information, however, more might be less, and perhaps the less vivid verbal information would become more integrated into memory. In Experiment 2, to provide some insight into the modality debate, we look at the number of false memories and the number of "Bugs detectors" across conditions where the false Bugs information is presented in pictorialonly, verbal-only, or both modalities. In Experiment 3, we use reaction time software and additional memory tests to unveil the level of consumer processing of the pictorial and verbal information.

\section{Experiment 1}

The purpose of this experiment was to determine whether true and false autobiographical advertising would be processed and influence memories in a similar manner. We expected that the false information would change what consumers re-membered about their experience at Disney. We expected that those who recognized the falseness of the ad claim at exposure would be less likely to create false memories than those who did not notice the discrepancy. 
FIGURE 1

Example of False Autobiographical Ad

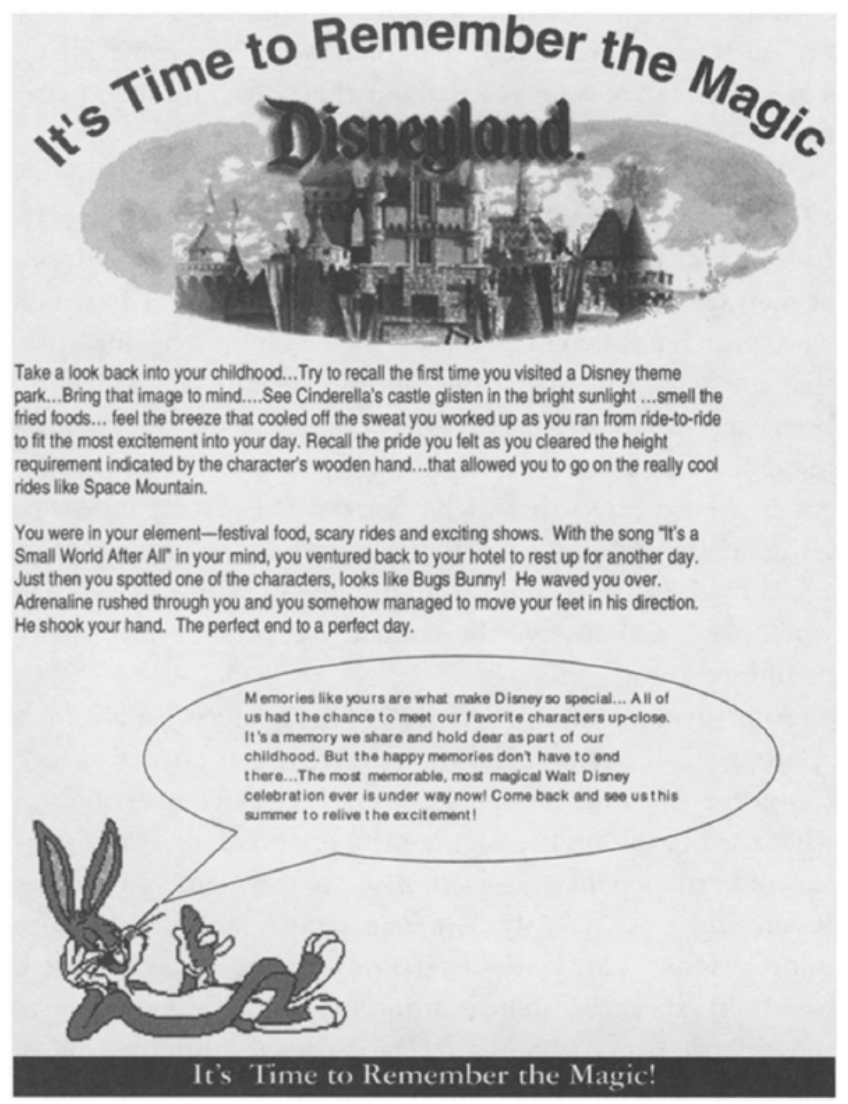

\section{Method}

Participants

Sixty-six undergraduates (32 female, 34 male) at a large North-western university participated in this experiment for course credit. The average age was 21. Participants were randomly assigned to one of two conditions.

Design

A single-factor (true/false advertising information) design was used. The ads were autobiographical in nature, compelling the reader to remember his or her own past experience by providing a vignette of a "typical" Disney experience, similar to the one used in Braun, Ellis, and Loftus (2002). An ex-ample of the false autobiographical ad appears in Figure 1.

The "truthful" ad featured the probable event of shaking hands with Mickey Mouse, whereas the "false" ad featured shaking hands with Bugs Bunny, who is a Warner Bros, character and would 
never have been part of a childhood experience at Disney. Either a picture of Bugs or Mickey appeared at the bottom of the ad, along with the textual mention of that character.

\section{Procedure}

The ads were passed out within a questionnaire in a mass class setting. Participants were told to read and evaluate it. They were then asked to rate their attitude, affect, and likelihood of visiting Disney in the future. Next, they were asked about their own past experience visiting Disney, and whether they had seen certain characters at the park. To keep the memory reports as constant across participants as possible, we asked them to write specifically about their earliest child-hood visit to the park. Last, they completed demographic in-formation and answered questions that measured demand. After the instructor collected the questionnaires, the participants received a short debriefing in which they learned about false memory research.

\section{Measures}

The main dependent measures can be divided into three groups: (1) those that asked about the advertisement and those that were given during exposure to the ad, (2) those that asked about attitudes toward Disney that immediately followed the ad measures, and (3) those that asked about participants' memories of visiting Disney as children. A full description of these measures appears in Appendix A.

\section{$\underline{\text { Results }}$}

\section{Coding Procedure}

Two independent judges coded respondents' reactions to the ads, and the recall statements of their Disney experience. Specifically, they coded the number of words participants used in response to the ad, whether their reactions to the ad were personal or concentrated on critiquing ad elements, and whether or not they noticed that Bugs Bunny did not belong in a Disney ad. For the memory measures, they coded the number of words in the recall statement and how many items that had appeared in the ad were mentioned as being part of the participants' own memory. The coders had no knowledge of the experimental hypotheses. Their interrater reliability was .9, and an average was used for the analysis.

\section{True Versus False Advertising}

Did the false information influence how consumers processed the advertising? Table 1 contains the means for both conditions on the ad processing, Disney, and memory measures. 
TABLE I

Experimental Means for Advertising, Brand, and Memory Measures

\begin{tabular}{|c|c|c|c|}
\hline Measure & False ad & True ad & Statistical tests \\
\hline \multicolumn{4}{|l|}{ Response to ad } \\
\hline Number of words & 50 & 46 & n.s. \\
\hline Personal or ad focused ( $1=$ personal focused, $0=$ ad focused) & .82 & .77 & n.s. \\
\hline Wells $R$ scale ( $1-10$ scale, higher $=$ more empathetic/involved $)$ & 5.8 & 5.7 & n.s. \\
\hline Attitude to the ad $(1-10$ scale, higher $=$ more positive $)$ & 7.0 & 7.1 & n.s. \\
\hline \multicolumn{4}{|l|}{ Disney measures } \\
\hline Attitude/likelihood to visit ( $1-10$ scale, higher = more positive) & 7.7 & 7.6 & n.s. \\
\hline Positive affect (1-10 scale, higher = more positive) & 6.6 & 6.7 & n.s. \\
\hline Negative affect $(1-10$ scale, higher = more negative) & 2.8 & 2.8 & n.s. \\
\hline \multicolumn{4}{|l|}{ Memory measures } \\
\hline Number of words & 21 & 17 & n.s. \\
\hline Mention of ad activities & 1.4 & 1.05 & n.s. \\
\hline Strength of memory $(\mathrm{I}-7$ scale, higher $=$ better recall) & 3.7 & 3.7 & n.s. \\
\hline Emotional involvement ( $1-5$ scale, higher = more involvement) & 3.6 & 3.7 & n.s. \\
\hline Pleasantness of experience $(-3$ to +3 scale, higher $=$ more pleasant $)$ & 1.8 & 1.9 & n.s. \\
\hline Personal importance $(1-10$ scale, higher $=$ more importance $)$ & 5.7 & 5.4 & n.s. \\
\hline Shake hands with Bugs $(I=$ yes, $0=$ no $)$ & $22 \%$ & $7 \%$ & $\chi^{2}(n=66)=3.8, p=.05$ \\
\hline Confidence - Bugs $(1-8$ scale, higher $=$ more confidence $)$ & 2.3 & 1.3 & $t(40)=1.72, p=.04$ \\
\hline
\end{tabular}

There were no significant differences between the true and false ad formats on any of the ad or brand-related measures, suggesting that the false information did not change how the consumers processed the ads or how they felt about Disney. In the coding of the response to advertising, however, we found that some participants who received the false Bugs information immediately noted the discrepancy in the advertising information, that Bugs was not connected to Disney (eight total). For example, one "Bugs detector" said: "Well, the picture of Disneyland looks great, and exciting colors add some character to it, but I see one problem with this ad, and that is that Bugs Bunny is NOT a Disney character. He is a Warner Bros, character, which throws the ad off."

Another participant said that the false information was affecting how she felt about Disney: "The glaring mistake of putting Bugs Bunny (he is Warner Bros.) just adds to the displacement of any positive feelings that the ad tries to convey through its memories. It's just really not attention-grabbing (except for asking what Bugs is doing in a Disney ad)." Unfortunately, the number of these detectors was too small to do a statistical analysis on the measures, but it appears from these and similar comments that these participants were not processing or integrating the advertising information in the same manner as those who accepted the Bugs information.

The next issue of interest was whether the recollections of participants who received the true advertising presentation would differ significantly from those who received the false advertising presentation. Overall, the memory measures did not differ across conditions on length, emotion, importance, or any of the measures mentioned in Table 1 . The only difference was in the identification of Bugs as having been part of their past experience; there was an overall effect of the false information, where those who received it recalled more Bugs memories than those who did not, $22 \%$ versus $7 \%$. (It 
was expected that even in the control condition, there might be some people who confused Bugs Bunny with their Disney memory due to exposure of Bugs in other venues; the comparison allows us to determine the effect of this particular advertising exposure.) This same pattern occurred for the "confidence in meeting Bugs" item, where there was an overall effect of the false information, $M=2.3$ for confidence in the false condition, versus $M=1.3$ in the true condition. As expected, those participants who detected the falseness of Bugs were unlikely to later say they met Bugs at the park.

\section{Demand Effect}

None of our participants guessed that the purpose of the experiment was to see whether the ad could alter their memory of a childhood experience. Most noted that they thought the purpose was to see how an ad could get consumers to remember their past, but few thought the ad changed what they had remembered.

\section{$\underline{\text { Discussion }}$}

The purpose of this experiment was to determine whether consumers would process true and false advertising differently, and whether such content choices would subsequently influence what they remembered about their past. If all participants in the false condition "caught on" as "Bugs detectors," we would question whether this paradigm would be appropriate for studying advertising $s$ ability to influence the past. However, we found that participants in both conditions became emotionally involved with the advertising, and this involvement led to the reconstruction of past visits to the park. The false information allowed us to determine whether the ad had an influence in altering the participant $s$ memory or if it had been primarily used to cue an existing memory. Had we not included that false information, we would not be able to determine whether the ad had, in fact, exerted a transformational effect on memory. For instance, one participant recalled shaking hands with Mickey Mouse during his childhood visit to Disney. Did that ever really happen to him? It could be a false memory based on the exposure to the "truthful" ad-maybe that never happened to him, but the ad made him believe it did.

There were some people, however, who did not become as involved with the false ad as with the true ad, because they detected the false information (as mentioned previously, we called these participants the "Bugs detectors"). In this case, the advertising was too discrepant from their own experience; this demonstrates the boundary condition for the advertising misinformation effect. This finding is consonant with per-suasion researchers, who find that incongruent information may stimulate greater thought (and perhaps distract attention from other parts) of the advertising (e.g., Meyers-Levy and Malaviya 1999). However, the number of "Bugs detectors" was too small here to gain much insight 
into how they were processing the false information differently from those who had accepted it. In the next experiment, we hoped to find out more information about the "Bugs detectors" and determine how they differ from those who use the ad to create false memories. These two measures could be viewed as proxy measures for those who embrace the ad (false memory creators) and those who discount it ("Bugs detectors").

\section{Experiment 2}

In Experiment 2, we varied how the false information was presented-either pictorially, verbally, or through both means-to see what aspect leads to the creation of false memories. In addition, as this experiment has the potential for more false memories as well as more "Bugs detectors," due to the greater amount of false information conditions, we hoped to further investigate what leads a person to create a false memory or to withstand such persuasion.

\section{Method}

Participants

One hundred (56 female, 44 male) undergraduates in a large Southeastern university participated in this experiment for course credit. They were randomly assigned to one of the three false information conditions.

Stimuli

All three ads were "false" in that they suggested that Bugs was associated with Disney. In the pictorial condition, this suggestion was conveyed by featuring a picture of Bugs at the bottom of the ad. In the verbal condition, it was conveyed with a headline on the ad saying, "Bugs Says It's Time to Remember the Magic," and then within the text by mentioning him as a character they might have shaken hands with as a child. In the "both" condition, it was conveyed using both types of false information.

Procedure

This experiment used the same procedure and measures as Experiment 1. 


\section{$\underline{\text { Results }}$}

\section{False Memories}

We found that there was a picture superiority effect: Both conditions that contained the false picture of Bugs resulted in the greatest number of false memories, with the pictorial-only condition creating the most false memories, $48 \%$, com-pared with the verbal presentation, $17 \%$, and both, $32 \%$, but only the pictorial- and verbal-only presentations were significantly different from one another (see Table 2). Confidence in meeting Bugs was also higher in the pictorial conditions, $M=4.7$ for pictorial only, versus $M=2.5$ for verbal only and $M=3.6$ for both.

Of interest was that the verbal-only condition, which resulted in the fewest false memories, also showed the greatest number of "Bugs detectors," 31\% ( $n=11)$ versus $12 \%(n=4)$ in the pictorial-only condition and $8 \%(n=3)$ in both. Both the comparisons between the pictorial- and verbal-only conditions and the comparison between verbal-only and both conditions were significantly different (see bottom of Table 2).

\section{"Bugs Detectors" Versus False Memory Creators}

Because we had a sizable number of "Bugs detectors" in this experiment $(n=17)$, we were able to investigate them in greater depth (see Table 3). We compared these detectors to those participants who had created false memories $(n=30)$. Our interest was whether the participants who discarded the ad information ("Bugs detectors") would process the ad, rate Disney, and report memories differently than those who had integrated the ad information into their own memory (i.e., the false memory creators). Some of the verbatim responses suggested this may be so. For example, one "Bugs detector" wrote: "Bugs Bunny isn't at Disney.... that distracted me while I read the ad because it gave me a sense that the ad was not really trying to plug into me remembering my Disney experience-rather, I looked for other clues for this to be a 'fake' ad." The false memory creators, on the other hand, focused more on their own experience while reading the ad: "I began to smile as I remembered the carefree days of my youth when my family made a trip to Disneyland, CA. I actually remember walking into Cinderella's castle with wide eyes and jaw dropped in won-der and amazement. When the ad mentioned the smells of foods... I remember how the continual onslaught of delicious smells made me so hungry all day. Our dad couldn't believe how four skinny little kids could pack away so much food. Disney has been a good memory for me for years!"

On more objective, quantifiable measures, where the number of words written was not significantly different, the false memory creators and the "Bugs detectors" showed the same initial 
effort in their response to the ad. The content of their responses, however, did differ significantly, where the false memory creators wrote a more personal account in their writ-ten response. This personal involvement was also shown in the Wells scale, where false memory creators scored higher than the "Bugs detectors" in emotional involvement with the advertising. Overall, attitudes toward the ad were more favorable in the case of false memory creators. Moreover, the "Bugs detectors'" negative feelings about the misleading ad affected how they felt about Disney in general. They showed higher negative affect, less positive affect, and less favorable attitudes and intention to revisit. (Refer to the bottom of Table 3 for the statistical tests on these measures.)

The memories recalled by these groups did not differ significantly in their length, clarity of recollection, emotional importance, or personal importance. Their memories were, however, influenced by whether or not they "bought" the advertising; the false memory creators had more pleasant memories and used more of the ad information in their recall than did the "Bugs detectors."

TABLE 2

Modality's Influence on Memory

\begin{tabular}{|c|c|c|c|c|c|c|}
\hline & \multicolumn{2}{|c|}{ Pictorial only } & \multicolumn{2}{|c|}{ Verbal only } & \multicolumn{2}{|c|}{ Both modalities } \\
\hline & False memories & Bugs detectors & False memories & Bugs detectors & False memories & Bugs detectors \\
\hline $\begin{array}{l}\text { Experiment } 2^{*} \\
\text { Experiment } 3^{* *}\end{array}$ & $\begin{array}{l}48 \% \\
52 \%\end{array}$ & $\begin{array}{l}12 \% \\
14 \%\end{array}$ & $\begin{array}{l}17 \% \\
29 \%\end{array}$ & $\begin{array}{l}31 \% \\
34 \%\end{array}$ & $\begin{array}{l}32 \% \\
52 \%\end{array}$ & $\begin{array}{l}8 \% \\
14 \%\end{array}$ \\
\hline \multicolumn{7}{|c|}{$\begin{array}{l}\text { * For Experiment } 2, \chi^{2} \text { tests between the conditions revealed that the overall difference in number of false memories was significant, } \chi^{2}(2 \text {, } \\
n=100)=7.37, p=.02 \text {. However, only the pictorial-only and verbal-only conditions were found to be significantly different from one another, } \chi^{2}(1 \text {, } \\
n=66)=7.39, p=.006\end{array}$} \\
\hline \multicolumn{7}{|c|}{$\begin{array}{l}\text { For the Bugs detectors in Experiment } 2,31 \%(n=11) \text { versus } 12 \%(n=4) \text { in the pictorial-only condition and } 8 \%(n=3) \text { in the both condition were } \\
\text { significantly different, } \chi^{2}(2, n=100)=6.76, p=.03 \text {. The comparison between the pictorial-only condition and the verbal-only condition was }\end{array}$} \\
\hline \multicolumn{7}{|c|}{$\begin{array}{l}\text { ** For Experiment } 3 \text {, the overall model for false memories was significantly different at } \chi^{2}(2, n=96)=5.03, p=.08 \text {. The pictorial-only condition was } \\
\text { found to be significantly different from the verbal-only condition, } \chi^{2}(1, n=62)=3.7, p=.05 \text {, and the both condition was significantly different from } \\
\text { the verbal-only condition, } \chi^{2}(1, n=68)=3.8, p=.04 \text {. }\end{array}$} \\
\hline \multicolumn{7}{|c|}{$\begin{array}{l}\text { The overall model for the Bugs detectors was significant, } \chi^{2}(2, n=100)=6.2, p=.04 \text {. The pictorial-only condition was found to be significantly } \\
\text { different from the verbal-only condition at } \chi^{2}(1, n=74)=4.14, p=.04 \text {, and from the both condition, also at } \chi^{2}(1, n=74)=4.14, p=.04 \text {. }\end{array}$} \\
\hline
\end{tabular}

\section{$\underline{\text { Discussion }}$}

The purpose of this experiment was to determine what modality would most influence consumers' memory of their past childhood experience. We remind the reader that while it looks like there might have been differences in involvement across conditions, the only thing we manipulated in this experiment was the type of misinformation. All participants had ample time to read the advertising (five minutes), so if one were to compare these results to persuasion studies that manipulate level of involvement, this experiment would probably fall closer to high rather than low involvement. 
We found the pictorial information to be highly influential in the false memory creation process. The verbal-only condition led to the greatest number of "Bugs detectors" and resulted in the fewest false memories. Overall, the "Bugs detectors" had less favorable responses to the ad and showed less involvement with the ad, and that negative affect transferred to their attitude toward Disney.

There are two ways to interpret the results on presentation modality. One possibility is that those in the verbal-only condition were processing the advertising at a deeper level (since they were more likely to detect Bugs), and were therefore less likely to create a false memory. The alternative explanation is that those in the verbal condition were not processing the advertising deeply enough. While there may have been some diligent consumers who did notice the Bugs information and rejected it, perhaps there were also some potential false memory creators who overlooked it because it was not as prominent as the picture. The picture may be what allows some consumers to embrace Bugs as being part of their own memory. For instance, one "Bugs detector" in the verbal-only condition wrote in response to the ad: "All I could think about was that Bugs Bunny is a Warner Bros, character and not a Disney character. This was a huge distraction."

\begin{tabular}{|c|c|c|c|}
\hline Measure & Bugs detectors & False memory creators & Statistical test \\
\hline \multicolumn{4}{|l|}{ Ad response } \\
\hline Number of words in response to ad & 32 & 35 & n.s. \\
\hline \% Personal responses to ad & $6 \%$ & $75 \%$ & $\chi^{2}(1, n=46)=14.9, p=.0001$ \\
\hline Wells $R$ scale & 4.1 & 7.6 & $t(44)=3.97, p=.01$ \\
\hline Attitude toward the ad & 4.9 & 7.4 & $t(44)=3.3, p=.001$ \\
\hline \multicolumn{4}{|l|}{ Disney measures } \\
\hline Negative affect & 3.3 & 2.1 & $t(43)=2.47, p=.01$ \\
\hline Positive affect & 4.4 & 6.5 & $t(44)=2.7, p=.008$ \\
\hline Attitude/likelihood of visiting & 7 & 8.6 & $t(44)=2.4, p=.01$ \\
\hline \multicolumn{4}{|l|}{ Childhood memory recall } \\
\hline Number of words & 11 & 13 & n.s. \\
\hline Clarity of recollection & 3 & 3.3 & n.s. \\
\hline Emotional importance & 3.2 & 3 & n.s. \\
\hline Personal importance & 5.8 & 5.6 & n.s. \\
\hline Pleasantness & -.3 & 1.6 & $t(42)=2.5, p=.01$ \\
\hline Use of ad information in recall & .16 & .73 & $t(39)=2.3, p=.02$ \\
\hline
\end{tabular}

To tease apart these explanations, we conducted Experiment 3, in which we added a memory test for the advertising information at the end of the session. We suggest that if deeper encoding of the advertising is occurring in the verbal conditions, participants would be more likely to recall the advertising information at a later time; if the alternative explanation prevails, then we would expect less memory for the advertising information in that condition compared with the other presentation conditions. We also thought it would be beneficial to utilize reaction time measures to explore what was happening in the case of pictorial-only and both presentation conditions. We chose a pictorial 
identification task, which is a better "match" for the false information and may lead to even more false memory identifications (Yamashita 1996).

In addition, we incorporated the IAT into our design. The extended Bugs categorization within the IAT also allowed us to determine how deeply the false information had been integrated. For instance, although the "both" condition did not show an enhancement in Experiment 2, it could be that in this more semantic-oriented task there would be an advantage to seeing the false information in both pictorial and verbal formats. It is noteworthy that other researchers have found the picture superiority effect more prominent in explicit memory tests than in implicit ones (Weldon and Roediger 1987). The verbal presentation may have more of an advantage on the implicit task, as modality effects have also been found in that area (and there lies the match between verbal presentation within the ad and test).

\section{Experiment 3}

The intent of this experiment was to further investigate how the presentation of false information within advertising-verbal, pictorial, or both modalities-affects how consumers process, and ultimately remember, their past childhood experiences targeted in the advertising. In this experiment, we allowed participants a longer time to recall their past memory, added a reaction time identification test to measure the accessibility of certain images in memory, and, in addition, included a memory test for the advertising itself to ascertain how well the advertising (and false advertising information) was originally encoded.

\section{Method}

Participants

One hundred ten (53 female, 57 male) undergraduates in a large Southeastern university participated in this experiment for course credit. They were randomly assigned to one of the three false information conditions.

Stimuli

The same ads used in Experiment 2 were used here.

\section{Procedure}

The participants were placed in groups of around thirty in a computer lab. They were handed the advertising information, and were asked to provide feedback on it for several minutes. They were 
then given 10 minutes to write about their own first childhood experience at a Disney resort. They filled out demographic questions and then proceeded to the computerized task. The computer task included two parts: recognition of items from their childhood visit to Disney, and then the IAT task (Appendix B contains a detailed explanation of this task). The main item of interest in the recognition test was the image of Bugs Bunny and whether participants identified him as part of the memory of their childhood experience and how confident they were that they did/did not meet him.

The second part was the IAT task, where the main interest was in whether participants would categorize Bugs Bunny as belonging to the Disney or "other" theme park category. Participants had a total of six trials in which they had to classify Bugs Bunny as either belonging to Disney or another venue.

Last, participants were given a written advertising memory test in which they were asked to recall everything they could remember from the Disney ad they had seen earlier in the hour. They were then asked to answer specific questions regarding the ad's content. The critical questions were: "What character did the child shake hands with?"; "What picture(s) appeared in the ad?"; and "What appeared in the ad's head-line?" These represented the parts of the ad that included the false information.

\section{$\underline{\text { Results }}$}

Initial Response to the False Information

As in Experiment 2, we found more "Bugs detectors" in the verbal-only condition, 34\%, than in either the pictorial-only, $14 \%$, or with both presentation styles, also at $14 \%$, and the pictorial-only and both conditions were significantly less than the verbal-only condition (see Table 2 for the statistics).

\section{Memory Recalls}

We hoped that the longer recollection session would result in participants incorporating the false information into their own memory stories (the prior studies only allowed several minutes for their recollection). We found one participant in the both condition who integrated Bugs into her memory story:

When I was 10, my parents took me and my sisters to Walt Disney World in Orlando, Florida. I remember that I was so excited. We all got up bright and early for the first day of excitement; we were going to the Magic Kingdom. This later was my most favorite place. As we entered the gates, the first thing I remember is seeing Chip and Dale. They were there to greet me and my family at the entrance. All I wanted to do is run around and have my picture taken with all the characters. I saw Bugs Bunny, 
Cinderella, Mickey and Minnie Mouse, and several other cartoon characters. I also got around 120 autographs. That day, the rides were not as appealing, because I loved the characters so much. I don't even remember eating that day, but I do know that when I got home I went through my autograph book, and reminisced on that day. It was great.

This female participant was 10 at the time of her visit, and visited the park again at age 12 . She was quite confident that her memory was veridical, giving us permission to send it home to her parents for their feedback (for another survey).

\section{False Memories}

As in Experiment 2, there were more false memories created in the pictorial conditions: $52 \%$ false identifications of Bugs for both the pictorial-only and both conditions, compared with $29 \%$ for the verbal-only condition (see the bottom of Table 2 for the statistical tests). It appeared that those who had received the pictorial-only information were faster, perhaps more "primed" than those in the other conditions, where processing may have been more "conscious." However, there was no significant difference in conditions in participants' response times to the false image: $2406 \mathrm{~ms}$ in both; $2021 \mathrm{~ms}$ in the pictorial-only condition; $2266 \mathrm{~ms}$ in the verbal-only condition. Nor was there a significant difference in confidence across conditions: 6.1 in both; 5.7 in the pictorial-only condition; 5.9 in the verbal-only condition. There was a greater advantage, however, on the Bugs classification task for false memory creators within the IAT for those who received the verbal in-formation; the overall model was significant at $F(2,42)=4.87, \mathrm{p}=.01$, with a greater tendency to consistently classify Bugs as being associated with Disney, $M=5.1$ for both, $M=5.3$ for the verbal-only condition, and $M=3.8$ for the pictorial-only condition. Tukey's post hoc comparisons revealed that the verbal-only and both conditions were significantly higher than the pictorial-only condition, at .05.

\section{Memory Test}

The advertising memory test was added as a means to gauge how well the false information had been originally encoded: greater recall would indicate more elaborate encoding; lesser recall, more superficial encoding. (See Table 4 for a summary of the results and the statistical tests.)

We found participants remembered significantly more items in the pictorial conditions, with an average of 6.2 items from the ad recalled in the both condition, 5.1 in the pictorial-only condition, and 4.7 in the verbal-only condition. Within those recall statements, we looked at whether participants had mentioned Bugs being part of the ad, and if so, whether they indicated seeing him in a picture or reading about him in the text or headline. As the dual-encoding explanation would predict, participants 
in the both condition had superior overall memory for Bugs, with $88 \%$ remembering him, compared with $76 \%$ in the pictorial-only condition and $47 \%$ in the verbal-only condition. It appeared that the picture was driving the better recall results: In the both condition, $67 \%$ of participants specifically mentioned the picture in their recall statements, compared with only $8 \%$ mentioning either the headline or shaking hands reference.

TABLE 4

Memory of Ad Material: Experiment 3

\begin{tabular}{|c|c|c|c|c|}
\hline Measures & Pictorial only & Verbal only & Both & Statistical tests \\
\hline No. of items recalled from ad & 5.1 & 4.7 & 6.2 & $\begin{array}{l}F(2,42)=4.87, p=.01 \text {. Post hoc } \\
\text { tests revealed that the both and } \\
\text { pictorial-only conditions were significantly } \\
\text { different from the verbal-only condition at } \\
\text { the } .05 \text { level. }\end{array}$ \\
\hline $\begin{array}{l}\text { Whether Bugs was } \\
\text { mentioned in recall }\end{array}$ & $76 \%$ & $47 \%$ & $88 \%$ & $\begin{array}{l}\chi^{2}(2, n=104)=14.6, p=.0007 \text {. The both } \\
\text { condition was significantly greater than the } \\
\text { verbal-only condition, } \chi^{2}(1, n=71)=12.9 \text {, } \\
p=.0003 \text {, and the pictorial-only condition } \\
\text { was greater than the verbal-only condition, } \\
\chi^{2}(1, n=71)=5.9, p=.01 \text {. }\end{array}$ \\
\hline $\begin{array}{l}\text { What picture appeared } \\
\text { in the ad? (Bugs) }\end{array}$ & $70 \%$ & $7 \%$ & $82 \%$ & $\begin{array}{l}\chi^{2}(2, n=104)=45, p<.0001 \text {; the two } \\
\text { pictorial groups were not significantly } \\
\text { different from one another. }\end{array}$ \\
\hline $\begin{array}{l}\text { What character did the } \\
\text { child shake hands with? (Bugs) }\end{array}$ & $6 \%$ & $37 \%$ & $42 \%$ & $\begin{array}{l}\chi^{2}(2, n=104)=12.5, p=.02 \text {. The both and } \\
\text { verbal-only conditions were not } \\
\text { significantly different from one another. }\end{array}$ \\
\hline $\begin{array}{l}\text { What was the headline that } \\
\text { was used in the ad? }\end{array}$ & $0 \%$ & $44 \%$ & $15 \%$ & $\begin{array}{l}\chi^{2}(2, n=104)=22, p<.000 I \text {; in this case, } \\
\text { the both condition and the verbal-only } \\
\text { condition were significantly different at } \\
\chi^{2}(1, n=7 \mid)=7.2, p=.007 \text {. }\end{array}$ \\
\hline
\end{tabular}

On the specific memory test items, the picture was remembered about equally well in the pictorial and both conditions, and few people in the verbal condition falsely remembered seeing the Bugs picture. Participants were about equal in their memory for the "shaking hands" item in the both and verbal-only conditions (and very few in the pictorial-only condition mistakenly remembered Bugs in the copy). The item that elucidated the most about processing was the headline question. There were significantly more people in the verbal-only condition who recalled the Bugs information correctly than in the other conditions, which indicates that participants in the verbal-only condition may have been merely reading the headline superficially and discarding the advertising information, whereas deeper processing may have been occurring in the other conditions, allowing for the creation of more reconstructed memories. 


\section{$\underline{\text { Discussion }}$}

The purpose of this experiment was to better understand why fewer false memories are created in the verbal-only condition. Was it because participants were more careful in their examination of the ad, or, alternatively, less likely to encode the false information? We found, as in Experiment 2, that there were more "Bugs detectors" in the verbal-only condition. This appears to be due to participants' attention to the ad's head-line, which was better remembered at a later time, suggesting that the ad content (which was not better remembered) was not processed as deeply as it was in the other conditions. The picture superiority effect on false recognition appeared to prevail, with both the pictorial conditions being more likely to create a false memory than the verbal-only condition. This episodic memory is likely to be more affected by the test modality, whereas seeing a match in the ad picture and ad test would help to enhance the false recognition process (Yamashita 1996). There were significantly more false memories when the picture recognition testing technique was employed (as compared with Experiments 1 and 2, when the recognition test was verbal).

The false verbal information appeared to be exerting a greater effect on semantic memory, where those who saw the name Bugs Bunny were more likely to consistently classify him as being associated with Disney. This implicit memory test was also in the same verbal format as the false verbal suggestion, so there may be effects due to modality there as well. The memory test revealed additional insights about the importance of having both verbal and pictorial information in the ad: There was better memory overall for the false implants.

This experiment demonstrates that false information received in an advertisement can have multiple layers of effect on consumers' later recollections. Although most of these intrusions are found in the more mundane recognition tasks, this experiment found that the possibility exists for even more conscious intrusion, as one participant (who received the ad with both pieces of misinformation), on her own accord, took that false information and incorporated it into her memory story.

\section{General Discussion}

The title of this paper poses the question, "How and when can advertising influence memory for consumer experience?" In a series of three experiments, we sought to provide insight into those questions. First, the "how." We found that when post-experience information alters consumers' recollection processes, it does so in the same manner as if an actual experience had been cued. We found that pictures were an important aspect of this cuing process. Looking at the difference in the 
number of created memories between the paper-and-pencil tests of Experiment 2 and the pictorial reaction time test of Experiment 3 provides some additional insight into the process. Notice the greater number of false identifications in Experiment 3, especially in the cases where participants saw the false information as a picture. It is suggested that the picture "primed" them to later rate Bugs Bunny as being part of their past experience. This priming effect was picked up better with the more implicit measure of Experiment 3. Yet the IAT demonstrated that this priming crossed modalities and influenced some participants' semantic memory structure, where they later came to consistently rate Bugs Bunny as belonging to the Disney category. The modality of the testing instrument is thus a critical decision advertisers need to consider when assessing advertising influence-words may access one type of memory, pictures another type.

When received only as a headline and within the longer text, the false words were more likely to be detected as "false," and less likely to be processed and integrated into consumers' memory than the pictorial information. When the false picture and words appeared together, however, they formed a stronger memory trace, influencing both implicit and explicit tests of memory. Having both modalities of misinformation may have made the false information seem more plausible. One participant noted the presence of Bugs Bunny when she received the ad, but really was not a "detector": "It made me think of being a little girl with my family. ... It makes me feel like a kid again, wanting to shake Bugs Bunny's hand." She seemed to feel that Bugs Bunny ought to be included in the ad-as if it was something she too remembered. Perhaps the picture was working at increasing participants' familiarity, as suggested by prior research (Hirschman 1986).

Now, the "when" aspect of the question: As other memory researchers have found (Dodson and Schacter 2001; Loftus 1979), the post-experience advertising will not alter memory for a prior experience if participants notice the discrepancy of the information-in the present case, the "Bugs detectors." This discrepancy detection occurred at the encoding of the advertisement, but had rippling affects on attitude and behavior. Indeed, participants who detected the false Bugs in-formation reported becoming less personally involved with the advertising, lower attitudes toward the advertising, more negative attitudes toward Disney, and were less likely to be influenced by the advertising material overall.

The somewhat paradoxical finding is that you want the consumer to be involved enough that they process the false information (Johar 1995) and make inferences from it, but not so involved that, as in this case, they notice the discrepancy between the advertising information and their own experience. While the FTC (Federal Trade Commission) may ban advertisers from presenting completely false 
information in their advertising, this finding suggests that advertisers not go too far in the puffery process if they want their information integrated and accepted as consumers' own. Deception falls in between false information and puffery on the information spectrum, and advertisers (and policymakers) ought to be aware that memory distortion may be an outcome of a misleading campaign.

This research has implications for researchers interested in engineering experiences, especially after-the-fact, and researchers seeking indirect means to measure advertising effects. These issues and future research ideas are discussed next.

\section{Reengineering Consumer Experience}

"We find that advertising works the way the grass grows. You can never see it, but every week you have to mow the lawn" (Tarshis, quoted in Mayer 1991). The very fact that advertising cues may serve as frames to alter past, current, and future experience is not surprising in light of current re-search on memory. This research challenges the implicit assumption of much advertising research that memory is generally veridical, fixed, and reproductive. As addressed here, these memory effects can also provide us some insights into the underlying constructive decision processes involved in the post-experience advertising situation.

It could be that there are similarities in messages intended to frame the consumer experience both before and afterward, for instance, conveying aspects of the consumption experience through the drama of the ad copy. An advertisement that refers to a common experience that many consumers can relate to, such as a holiday ritual or a theme park experience, has the potential to draw people into the ad. This may cause consumers to imagine themselves in the advertised event, vicariously experiencing the ritual as it is currently presented in the ad and conjuring up their own past experience (Boiler 1990; Deighton, Romer, and McQueen 1989; Wells 1986).

There may also be aspects where the forward and backward framing differ, however. For instance, it is not clear that the pictorial cue would outweigh the verbal one when it precedes the experience. The pictorial aspect is an important part of consumers' recollection processes, and thus is important when reframing a past experience. One of the unifying aspects of the forward and backward framing findings is the agreement that consumers are generally unaware of the influence advertising has had on the interpretation of their experience, whether as a memory or as a perception. This means that more traditional self-report measures of advertising usage may be grossly underestimating the impact of advertising. Because of this more insidious effect on consumers, advertising re-searchers are urged to find more indirect measures to assess influence. 


\section{Implications for Advertising Researchers}

Although cognitive research on false memories has not been a focal point in advertising journals, the effects of a reconstructive memory system have been noted by advertising researchers for some time. Advertisers are quite aware that false recognition of their advertising may occur-referred to as "slippage" due to competitive factors (Sutherland and Fried-man 2000). Furthermore, classic advertising research has found consumers have "recognized" ads they were never exposed to (e.g., Appel and Blum 1961; Lucas and Murphy 1939). These memory errors are due to an overloaded memory system that "reconstructs" and attempts to "make sense" out of the past.

Of continual debate within the academic and practitioner world of advertising research has been the relevance of academic studies performed on undergraduates. Cornelissen and Lock suggest that theoretical academic articles can advance advertising thought and practice in symbolic ways: "Instead of offering specific technical advice with direct application, academic articles on advertising theory present information of conceptual and symbolic value of practitioners, suggesting different worldviews of organizational life" (2002, p. 54). The false memory paradigm was introduced here as a means to demonstrate that advertising can not only cue an existing memory in its execution, as many of the nostalgia type ads attempt to do, but through this cuing process, lead to memories that become more consistent with the advertisers' portrayal of reality than what, in fact, may have occurred during the consumer's own past.

Braun (1999) suggested that memories that were enhanced and rehearsed with post-experience advertising were stronger and held with more confidence than memories that had not received such post-experience support. We found here that an autobiographical ad led to consumer memories that were consistent with the advertising message, but the only way to determine whether the advertising information had, in fact, influenced the memory was to consider the role of the false information.

We understand that the existence of "false memories" may not be considered a favorable quality to the advertiser, and we do not support the intentional altering of consumers' pasts. We suggest, however, that advertisers may be doing this any-way, especially in campaigns that reference past experiences that not all consumers have had. Because true and false memories are recalled in similar ways, the findings of the false memory creators provide insight to advertisers interested in developing copy and images that best bring back the consumers' past. In fact, one could conceive of advertisers using a similar false memory design to determine what version of their own campaign may most influence the past. Rather than probing memory about the advertising itself, this paradigm al-lows 
researchers to assess whether the ad information becomes integrated into the source of information consumers say they rely on most in their decision making-their own experience.

In addition to the false memory paradigm, this research discussed how reaction time tests could be incorporated into advertising testing. These implicit tests come closer to measuring consumers' imagery regarding the advertising, which they might not have been able to verbalize in a more traditional self-report situation.

\section{Limitations and Future Research}

Our studies were conducted within a narrow context of potential false memories? - memories for childhood experiences. This context, one could argue, would be easier to change than a memory coming from a more recently experienced encounter if it weren't for the fact that the experience targeted was what many consider (our participants included) a monumental childhood event. Thus far, the majority of false advertising research focused on childhood events has used the Disney/ Bugs experience (e.g., Braun, Ellis, and Loftus 2002). Future research ought to consider targeting memories from different moments in consumers' lives, as well as focusing across different product categories. An interesting investigation would be to consider what type of products might benefit most with such a memory/experiential focus.

The false memory paradigm allows the researcher to study the influence of particular experimental factors on consumers' retention of advertising information; the verbal versus pictorial debate is only one advertising debate that could be better understood through this design. For instance, to tie this research together with the forward framing research, one might investigate the order of information presentation: Is an ad received before an experience more successful in trans-forming it in memory than an ad received afterward?

Other research might consider expanding the modality is-sue to include radio, television, and print ads to determine which medium is most influential in modifying consumer memory. Individual differences in response to advertising also ought to be examined; memory researchers find that both the very young and the very old tend to be more susceptible to false suggestions than the population at large. Both these groups are viewed as "protected classes," and policymakers who feel that a particular campaign may be "crossing the line" could put it to test in this paradigm to determine if it is, indeed, creating false memories.

The reconstructive memory process allows consumers to think, retain, and integrate information from various sources. The false memories highlighted in this research are one of the 
negative consequences of this dynamic system. To know that a memory is reconstructed and not necessarily a veridical representation does not make it any less meaningful or enjoyable at the time the person is remembering an event. The advertising researcher needs to consider the emotional consequences of memory, as well as the multiple layers of effect it has on consumer judgments. Memory is a complex system: At times we are able to recall experiences from early childhood; other times we cannot even remember a phone number read to us by a 411 operator. Different techniques are needed to uncover the many levels of memory; recall and recognition tests employed by most advertising researchers only get at the tip of the iceberg.

\section{References}

Aaker, David A., and Douglas M. Stayman (1992), "Implementing the Concept of Transformational Advertising," Psychology and Marketing, 9 (May/June), 237-253.

Appel, Valentine, and Milton L. Blum (1961), "Ad Recognition and Respondent Set," Journal of Advertising Research, 1 (June), 13-21.

Bartlett, Frederic C. (1932), Remembering, Cambridge: Cambridge University Press.

Baumgartner, Hans, Mita Sujan, and James R. Bettman (1992), "Autobiographical Memories, Affect and Consumer Information Processing," Journal of Consumer Psychology, 1 (1), 53-82.

Belli, Robert F., and Elizabeth F. Loftus (1996), "The Pliability of Autobiographical Memory: Misinformation and the False Memory Problem," in Remembering Our Past: Studies in Autobiographical Memory, David C. Rubin, ed., Cambridge: Cam-bridge University Press, 157179.

Boller, Gregory W. (1990), "The Vicissitudes of Product Experience: 'Songs of Our Consuming Selves' in Drama Ads," in Advances in Consumer Research, Marvin E. Goldberg, Gerald J. Gorn, and Richard W. Pollay, eds., Provo, UT: Association for Consumer Research, 17, 621-625.

Boulding, William, Ajay Kalra, Richard Staelin, and Valarie Zeithaml (1993), "A Dynamic Process Model of Service Quality: From Expectations to Behavioral Intentions," Journal of Marketing Research, 30 (February), 7-27.

Braun, Kathryn A. (1999), "Post-experience Advertising Effects on Consumer Memory," Journal of Consumer Research, 2 (March), 319-334.

, and Elizabeth F. Loftus (1998), "Advertising's Misinformation Effect," Applied Cognitive Psychology, 12 (December), 569-591. 
—, Rhiannon Ellis, and Elizabeth F. Loftus (2002), "Make My Memory: How Advertising Can Change Our Memories of the Past," Psychology and Marketing, 19 (January), 1-23

Childers, Terry L., and Michael J. Houston (1984), "Conditions for a Picture Superiority Effect on Consumer Memory," Journal of Consumer Research, 11 (September), 643-654.

Clark, E. (1985), The Want Makers: Inside the World of Advertising, New York: Penguin Books.

Cornelissen, Joep P., and Andrew R. Lock (2002), "Advertising Research and Its Influence on Managerial Practice," Journal of Advertising Research, 42 (3), 50-55.

Deighton, John (1984), "The Interaction of Advertising and Evidence," Journal of Consumer Research, 11 (December), 763- 770.

— and Robert M. Schindler (1988), "Can Advertising Influence Experience?" Psychology and Marketing, 5 (Summer), 103-115.

— , Daniel Romer, and Josh McQueen (1989), "Using Drama to Persuade," Journal of Consumer Research, 16 (December), 335-344.

Dodson, Chad S., and Daniel L. Schacter (2001), '"If I Had Said It I Would Have Remembered It': Reducing False Memories with a Distinctiveness Heuristic," Psychonomic Bulletin and Review, 8 (March), 155-161.

Edell, Julie A., and Richard Staelin (1983), "The Information Processing of Pictures in Print Advertisements," Journal of Consumer Research, 10 (June), 45-61.

Ehrenberg, Andrew, Neil Barnard, Rachel Kennedy, and Helen Bloom (2002), "Brand Advertising as Creative Publicity," Journal of Advertising Research, 42 (4), 7-19

Franzen, Giep, and Margot Bouwman (2001), The Mental World of Brands, WARC, U.K.: World Advertising Research Centre.

Gardner, Meryl P., and Michael J. Houston (1986), "The Effects of Verbal and Visual Components of Retail Communications," Journal of Retailing, 62 (Spring), 64-78.

Garry, Maryanne, Charles G. Manning, Elizabeth F. Loftus, and Stephen J. Sherman (1996), "Imagination Inflation: Imagining a Childhood Event Inflates Confidence That It Occurred," Psychonomic Bulletin and Review, 3 (2), 208-214.

Greenwald, Anthony G., Debbie E. McGhee, and Jordan L. K. Schwartz (1998), "Measuring Individual Differences in Implicit Cognition: The Implicit Association Test," Journal of Personality and Social Psychology, 74, 1464-1480.

Hall, Bruce F. (2002), "A New Model for Measuring Advertising Effectiveness," Journal of Advertising Research, 42 (2), 23-32. 
Hirschman, Elizabeth C. (1986), "The Effect of Verbal and Pictorial Advertising Stimuli on Aesthetic, Utilitarian and Familiarity Perceptions," Journal of Advertising, 15 (2), 27-35.

Hoch, Stephen J. (2002), "Product Experience Is Seductive," Journal of Consumer Research, 29 (3), 448455.

_ and John Deighton (1989), "Managing What Consumers Learn from Experience" Journal of Marketing, 53 (April), 1-20.

Hunter, Ian Melville Logan (1964), Memory, London: Penguin Books.

Johar, Gita Venkataramani (1995), "Consumer Involvement and Deception from Implied Advertising Claims," Journal of Marketing Research, 32 (August), 267-279.

Johnson, Marcia K., Mary A. Foley, Aurora F. Suengas, and Carol L. Raye (1988), "Phenomenal Characteristics of Memories for Perceived and Imagined Autobiographical Events," Journal of Experimental Psychology: General, 117 (December), 371- 376.

Keller, Kevin L. (1987), "Memory Factors in Advertising: The Effect of Advertising Retrieval Cues on Brand Evaluations," Journal of Consumer Research, 14 (December), 316-333.

- (1991), "Cue Compatibility and Framing in Advertising," Journal of Marketing Research, 28 (February), 42-57.

Lampinen, James M., and Vicki L. Smith (1995), "The Incredible (and Sometimes Incredulous), Child Witness: Child Witnesses' Sensitivity to Source Credibility Cues," Journal of Applied Psychology, 80 (October), 621-627.

Lodish, Leonard M., Magid Abrahamson, Stuart Kalmenson, Jeanne Livelsberger, B. Lubetkin, B. Richardson, and M. E. Stevens (1995), "How TV Advertising Works: A Meta-analysis of 389 Real World Split Cable TV Advertising Experiments," Journal of Marketing Research, 32 (May), 124? 139.

Loftus, Elizabeth F. (1977), "Shifting Human Color Memory," Memory and Cognition, 5, 696.

(1979), "Reactions to Blatantly Contradictory Information," Memory and Cognition, 7, 368-374. (1982), "Memory and Its Distortions," G. Stanley Hall Lecture Series, Washington, DC: American Psychological Association.

— 720-725.

Lucas, Darrell B., and M.J. Murphy (1939), "False Identification of Advertisements in Recognition Tests," Journal of Applied Psychology, 23, 264-269. 
Mayer, Martin (1991), Whatever Happened to Madison Avenue? Advertising in the 90s, Boston: Little, Brown.

Meyers-Levy, Joan, and Prashant Malaviya (1999), "Consumers' Processing of Persuasive Advertisements: An Integrative Framework of Persuasion Theories," Journal of Marketing, 63, 45-60.

Neisser, Ulric (1982), Memory Observed, San Francisco: W.H. Freedman.

Olson, Jerry C, and Phillip A. Dover (1979), "Disconfirmation of Consumer Expectations Through Product Trial" Journal of Applied Psychology, 64 (April), 179-189.

Paivio, Allan (1971), Imagery and Verbal Processes, New York: Holt, Rinehart and Winston.

Pezdek, Kathy (1977), "Cross-modality Semantic Integration of Sentence and Picture Memory" Journal of Experimental Psychology: Human Learning and Memory, 3, 515-524.

— Kimberly Finger, and Danelle Hodge (1997), "Planting False Childhood Memories: The Role of Plausibility," Psychological Science, 8 (November), 437-441.

Phillips, Barbara J. (2000), "The Impact of Verbal Anchoring on Consumer Response to Image Ads," Journal of Advertising, 29(1), 15-24.

Reber, Arthur S. (1985), Dictionary of Psychology, London: Penguin Books.

Rossiter, John R., and Larry Percy (1980), "Attitude Change Through Visual Imagery in Advertising," Journal of Advertising, 9(2), 10-16.

Schacter, Daniel (1996), Searching for Memory, New York: BasicBooks. , Wilma Koutstaal, Martha Johnson, and M. S. Gross (1997), "False Recollection Induced by Photographs: A Comparison of Older and Younger Adults," Psychology and Aging, 12(2), 203215.

Schmitt, Bernd H. (1994), "Contextual Priming of Visual Information in Advertisements," Psychology and Marketing, 11(1), 1-14.

Smith, Ruth Ann (199D, "The Effects of Visual and Verbal Advertising Information on Consumers' Inferences," Journal of Advertising, 20(4), 13-25.

Stafford, Maria Royne (1996), "Tangibility in Services Advertising: An Investigation of Verbal Versus Visual Cues," Journal of Advertising, 25 (3), 13-29.

Sutherland, Max, and Larry Friedman (2000), "Do You Model Ad Awareness or Advertising Awareness?" Journal of Advertising Research, 40 (5), 32-37.

Tousignant, James P., David Hall, and Elizabeth F. Loftus (1986), "Discrepancy Detection and Vulnerability to Misleading Postevent Information," Memory and Cognition, 14, 329-338. 
Wade, Kimberley A., Maryanne Garry, Don J. Read, and Stephan Lindsay (2002), "A Picture Is Worth a Thousand Lies: Using False Photographs to Create False Childhood Memories," Psychonomic Bulletin and Review, 9 (September), 597-603.

Weldon, Mary S., and Henry L. Roediger (1987), "Altering Retrieval Demands Reverses the Picture Superiority Effect," Memory and Cognition, 15 (July), 269-280.

Wells, William D. (1986), "Three Useful Ideas," in Advances in Consumer Research, vol. 13, Richard J.

Lutz, ed., Provo, UT: Association for Consumer Research, 9-12.

Yamashita, Masako (1996), "A Re-examination of the Misinformation Effect by Means of Visual and Verbal Recognition Tests," Japanese Psychological Research, 38, 47-52.

Yi, Youjae (1990), "Direct and Indirect Approaches to Advertising Persuasion: Which Is More Effective?" Journal of Business Research, 20 (4), 279-292.

Zaltman, Gerald (1997), "Rethinking Market Research: Putting People Back In," Journal of Marketing Research, 34 (4), 424- 437.

Zaragoza, Maria S., and Karen J. Mitchell (1996), "Repeated Exposure to Suggestion and the Creation of False Memories," Psychological Science, 7 (September), 294-300.

\section{Appendix A- Measures Presented at Advertising Encoding/Exposure}

\section{Free Response}

Marketers target consumers with different types of advertising messages. There are many ways to judge aft ad's effectiveness. Here we're interested in your own personal reflections of the ad-how it made you feel, what it made you think about.

We want you to read it, elaborating and imaging its content. In the space provided below, write down what went through your mind as you were reading the ad. Don't hold back. Try to write as much as you can. All can be helpful. There's no rush...you'll have five minutes to complete this and answer several advertising scales that appear at the end of this page and on the next page.

\section{Attitude Toward the Ad}

How would you rate the ad overall?

1

\section{Unfavorable}

$\begin{array}{llll}2 & 3 & 4 & 5\end{array}$

6

7

8

9 10

Favorable 


$\begin{array}{llllllllll}1 & 2 & 3 & 4 & 5 & 6 & 7 & 8 & 9 & 10\end{array}$

Bad

1

2

3

4

5

6

7

8

9

Unpleasant

1

2

3

4

5

6

7

8

9

Pleasant

\section{Negative}

Wells R Scale

How involving was the ad for you? Fill out the following scales:

I felt I was right there in the ad, experiencing the situation again.
1

2
3
4
5
6
7
8
9
10

\section{Strongly}

Disagree

Strongly

Agree

I really got involved in the feelings provoked by the ad.

1

2

3

4

5

6

7

8

9

10

Strongly

Disagree

While I was looking at the ad, I could easily put myself in the situation.

Strongly

Agree $\begin{array}{llllllll}1 & 2 & 3 & 4 & 5 & 6 & 7\end{array}$

Strongly

Disagree
8

9

$9 \quad 10$

Strongly

Agree

While looking at the ad, I felt that the events were happening to me.

1

2

3

4

5

6

7

8

9

10

Strongly

Agree

Strongly

Disagree 


$\begin{array}{llllllllll}1 & 2 & 3 & 4 & 5 & 6 & 7 & 8 & 9 & 10\end{array}$

\section{Unfavorable}

1

Bad
2

3

4

5

6

5

5

4

5

6
Favorable

10

Good

10

Pleasant

10

Positive

\section{Negative}

7

8

9

Likelihood of (re)visiting a Disney ${ }^{\mathrm{TM}}$ resort:

$\begin{array}{lrlllllll}1 & 2 & 3 & 4 & 5 & 6 & 7 & 8 & 9\end{array}$

\section{Affect Scales}

We are also interested in your feelings toward Disney ${ }^{\mathrm{TM}}$. Below you'll see a list of words, and underneath each, a scale. Mark toward the end of the scale how well that word represents your feelings toward Disney $^{\mathrm{TM}}$ [The scales were anchored by $1=$ strongly disagree, $10=$ strongly agree. The words that represented positive affect were: joyous, affectionate, loving, sentimental, exciting, happy, satisfying, delighted, proud, fond. The words that represented negative affect were: embarrassing, annoying, frustrating, angry, fearful, regretful, sad, nervous. "Surprising" was not included because it was not found to correlate with either the positive or negative words.]

\section{Memory of Visiting Disney as a Child}

Free Recall

Have you ever been to ANY of the Disney ${ }^{\mathrm{TM}}$ resorts? $\quad \mathrm{Y} \quad \mathrm{N}$

At approximately what age did you visit? ___ _ (Please list all visits)

What happened during your earliest visit to the resort (under the age of 10)?

Recall Scales

How well did you remember your earliest childhood experience? 


\begin{tabular}{lllrrrr}
\multicolumn{1}{c}{1} & 2 & 3 & 4 & 5 & 6 & 7 \\
$\begin{array}{l}\text { Not at } \\
\text { all }\end{array}$ & $\begin{array}{l}\text { Barely } \\
\text { at all }\end{array}$ & $\begin{array}{l}\text { Not so } \\
\text { well }\end{array}$ & $\begin{array}{l}\text { Fairly } \\
\text { well }\end{array}$ & $\begin{array}{l}\text { Very } \\
\text { Well }\end{array}$ & $\begin{array}{l}\text { Almost } \\
\text { perfectly }\end{array}$ & Perfectly
\end{tabular}

Rate the pleasantness of your childhood visit using the following scale. (Circle one)

$-3$

Extremely unpleasant
$-2 \quad-1 \quad 0$

Neutral
1

2 Extremely
pleasant

What was your emotional involvement in your visit to the resort?

1

Nothing
2

Little
3

Moderate
4

Considerable
5

Extreme

Rate the personal importance of this visit to your childhood:

1

2

3

4

5

6

7

8

9

10

Trivial

Very Important

\section{$\underline{\text { Recognition }}$}

Disney is interested in what childhood characters young adults remember meeting at the resort. Please indicate your confidence that you met the following characters when you were under 10 years old. [Bugs appeared third on the list, with scales anchored by $1=$ not very confident, $10=$ very confident.]

Which characters did you actually meet in person (e.g., "shake their hand")? Place an X in front of all characters you met personally under the age of 10. [Bugs appeared third on the list.]

\section{Appendix B-Computerized Task Instructions}

The recognition task began with these instructions, which appeared on participants' computer screens:

We're interested in what people, places, and things you remember from your earliest visit to a Disney resort. For this part of the study you will be presented with pictures of rides, attractions, and characters. Some are from Disney; others are not. We want you to indicate, whether or not the image you see is something you remember experiencing during your visit by pressing the $Y$ 
key if so, and the $N$ key if not. Please try to react as fast as possible. Following your answer, you will be asked to indicate how confident you are in your response. Press any key to start.

An image of Donald Duck then appeared, and after pressing either $\mathrm{Y}$ or $\mathrm{N}$, the following statement appeared on the screen:

If you indicated $Y$, how confident are you? [where $1=$ not very confident, 7 = very confident]. If you indicated N, how confident are you that you DID NOT experience the previous image during your childhood visit to Disney? [where 1 = not very confident, 7 = very confident].

Images of Sebastian, Mickey, and then the critical Bugs Bunny appeared, after which other characters and rides appeared so as to not draw attention to the purpose of this task.

The IAT (Implicit Association Test) was introduced with the following:

In the next task you will be presented with a set of words to classify into groups, such as words representing Disney or associated with other theme parks and entertainment venues. Be sure to notice the concept names at the top of the screen [Disney appeared on participants' left; "Other" was seen on their right]. Press e FAST for words described by the left concept name. Press / FAST for words represented by the right concept name. $X$ will appear when you press the wrong key. Whenever X appears, press the other key immediately. Press the spacebar to proceed. GO FAST. Some mistakes are OK.

The participants then began their IAT session. These word choices came from the IAT site, https://www.implicit.harvard.edu/im-plicit/. The critical categorization task involved the Disney/other trial where the Disney words consisted of Euro Disney, Mickey Mouse, Space Mountain, Goofy, Disneyland, Peter Pan, Walt Disney World, Epcot, and the non-Disney words were Universal Studios, Sea World, Sylvester, Busch Gardens, Six Flags, Visionland, Daffy Duck, Tweety. Bugs Bunny appeared within this trial, but unlike the other words, no $X$ appeared if he was incorrectly identified as being part of Disney. The experiment was then repeated with the concept names changing sides. 